\title{
Pastejo e nitrogênio sobre o crescimento de raízes na mistura de aveia preta e azevém
}

\section{Grazing and nitrogen on the growth of roots in the mixture of oat and ryegrass}

\author{
Hugo von Linsingen Piazzetta ${ }^{*}$; Anibal de Moraes²; Ticiany Maria Dias Ribeiro ${ }^{3}$; \\ Itacir Eloi Sandini'; Sebastião Brasil Campos Lustosa ${ }^{4}$; Adelino Pelissari ${ }^{5}$
}

\section{Resumo}

Este trabalho objetivou avaliar os efeitos do pastejo e sua ausência e doses de nitrogênio (N) sobre a morfologia de raízes da mistura de aveia preta (Avena strigosa Schreb.) e azevém anual (Lolium multiflorum Lam.). O delineamento experimental foi de blocos cazualizados em parcelas subsubdivididas, na parcela principal foram estudados os efeitos do pastejo e de sua ausência, na subparcela as doses de $\mathrm{N} 75 \mathrm{e} 150 \mathrm{~kg} \mathrm{ha}^{-1} \mathrm{e}$ as sub-subparcelas às épocas de amostragens. Foi utilizado o método do cilindro para coleta de raiz, sendo mensurados o comprimento, área superficial, diâmetro médio e volume radical pelo sistema de análise de imagem Win/MacRizho (4.1c). Determinou-se a massa seca radical e da parte aérea e estimou-se a massa específica do tecido radical e a relação parte aérea: raiz. A partir destes resultados se calculou a taxa de crescimento relativo de raiz (TCRR), taxa de expansão relativa de raiz (TERR) e taxa de acúmulo de matéria seca diária (TAMS). No primeiro período, ocorreu maior TCRR e TERR, no segundo período ocorreu redução dos mesmos, provavelmente devido ao déficit hídrico e senescência das plantas. Também houve redução da TAMS devido ao pastejo. Com pastejo, o comprimento, área da superfície, diâmetro médio e volume radical foram maiores, indicando que houve maior crescimento radical de plantas pastejadas em comparação às não pastejadas. Os sistemas estudados não tiveram efeito sobre a massa seca radical. Foi observado maior massa específica e relação parte aérea: raiz no sistema sem pastejo. Não houve diferença significativa entre as doses de nitrogênio estudadas. Na mistura de aveia preta e azevém, o pastejo e doses de $\mathrm{N}$ até $150 \mathrm{~kg} \mathrm{ha}^{-1}$ pouco afetam o crescimento radical. As doses de adubação nitrogenada alteraram pouco as taxas de crescimento e expansão radical. Por outro lado, o pastejo favoreceu o comprimento, área, volume e diâmetro radical. Palavras-chave: Comprimento de raiz, diâmetro de raiz, massa radicular, relação parte aérea: raiz, taxa de crescimento relativo de raiz, volume de raiz

\footnotetext{
Abstract

This study evaluated the effect of grazing and its absence, and the nitrogen on the morphology of roots of black oat (Avena strigosa Schreb.) mixed with Italian ryegrass (Lolium multiflorum Lam.). The experimental design was a randomized block design in split-split, the main portion was study the effects of grazing and its absence, in the subplots the nitrogen doses of 75 and $150 \mathrm{~kg} \mathrm{ha}^{-1}$ and

${ }^{1}$ Prof. Adjunto, Universidade Federal da Fronteira Sul, UFFS, campus Erechim, Erechim, RS. E-mail: hugo.piazzetta@uffs.edu.br

${ }^{2}$ Prof. Adjunto, Universidade Federal do Paraná, UFPR, Curitiba, PR. E-mail: anibaldemoraes@gmail.com

${ }^{3}$ Prof $^{\mathrm{a}}$, Faculdade Ideau, Getúlio Vargas, RS. E-mail: ticiany.ribeiro@gmail.com

${ }^{4}$ Profs. Adjuntos, Universidade Estadual do Centro-Oeste, UNICENTRO, Guarapuava, PR. E-mail: isandini@hotmail.com; slustosa@unicentro.br

${ }^{5}$ Prof. Associado, Universidade Federal do Paraná, UFPR, Curitiba, PR. E-mail: linopeli@hotmail.com

* Autor para correspondência
} 
in the sub-subplots were at sampling period. There was used the cylinder method to collect the root, being measured the length, surface area, mean diameter and volume by image analysis system Win / MacRizho (4.1c). Determined the dry mass of roots and shoot, and estimated the density of the root tissue and shoot:root ratio. From these results we determined the rate of root growth relative (RGR), relative root expansion rate (RRER) and rate of accumulation of dry matter daily (RADM). In the first period, was higher RGR, RRER, the second period there was a reduction of the same, probably due to the period of drought and plant senescence. There was also reduced due to grazing RADM. With grazing, the length, surface area, mean diameter and root volume were higher, indicating that there was greater root growth of plants grazed compared to ungrazed. The systems studied had no effect on the dry weight of roots. There were found greater specific mass and shot:root ratio in the system without grazing. There was no significant difference between the nitrogen studied. At mixed of black oat and ryegrass, the grazing and nitrogen dose until $150 \mathrm{~kg} \mathrm{ha}^{-1}$ little affect root growth. The nitrogen dose changed a little the growth rates and expansion of the roots. On the other hand, the grazing favored the length, area, volume and root diameter.

Key words: Root length, root diameter, root mass, shoot: root ratio, relative growth rate of root, root volume

\section{Introdução}

Pastagens misturadas de aveia e azevém tem sido amplamente estudadas visando definir práticas de manejo mais eficientes. Em geral, nessas pesquisas, foram consideradas somente a parte aérea das plantas, como o perfilhamento, crescimento e a proporção de folhas e de colmos na estrutura das plantas e o índice de área foliar; dentre outros caracteres descritivos de plantas. Porém, a produtividade da parte aérea está relacionada ao desenvolvimento radical uma vez que ocorre interação entre elas (GIACOMINI et al., 2005). A maior dificuldade para se estudar o crescimento, volume e o diâmetro de raízes em culturas forrageiras está no fato das metodologias serem bastante trabalhosas e dispendiosas (DA CUNHA et al., 2010). Porém, o entendimento do seu crescimento tem elevado grau de importância no desenvolvimento e manutenção das plantas na paisagem.

As raízes não são responsáveis apenas pela absorção de água e nutrientes que irão garantir o aporte nutricional necessário para o desenvolvimento da parte aérea (EISSENSTAT; YANAI, 1997), mas também são fundamentais para o acúmulo de reservas de energia fotoassimilada pelas folhas (HAVEN; EVERT; EICHHORN, 1996), principalmente em raízes mais grossas
(EISSENSTAT et al., 2000). Atenção tem sido dada ao componente raiz na medida em que este pode acrescentar matéria orgânica aos solos, e assim propiciar melhorias na porosidade e na matéria orgânica dos solos, podendo também promover a descompactação dos solos (GREENWOOD; MCKENZIE, 2001).

O desenvolvimento do sistema radical está relacionado com o ambiente onde a planta está inserida, onde fatores como: o ciclo de desenvolvimento da cultura que determina maior taxa de crescimento durante a fase vegetativa (FLOSS, 2011), a disponibilidade hídrica (FRANK, 2007), a disponibilidade de nutrientes (CECATO et al., 2001) e a intensidade com que as folhas são removidas (CECATO et al., 2001; MORVANBERTRAND et al., 1999) podem resultar em benefícios ou prejuízos ao desenvolvimento das raízes.

Caldwell (1987) comentou que a planta utiliza quantidade considerável de fotoassimilados para produção de raízes. Por sua vez, a espécie vegetal, o tipo de raiz e, sobretudo, o ambiente, afetam a longevidade de vida de raízes (EISSENSTAT; YANAL, 1997). Isso se torna importante, pois o constante surgimento e morte de raízes correspondem à grande quantidade de carbono acumulado no solo e a manutenção da sua matéria orgânica. 
Quando uma planta sofre herbivoria (desfolha), ocorre alteração no fluxo de carbono e nitrogênio da planta, ou seja, após a remoção da parte aérea, as plantas remobilizam reservas das raízes para rebrota das folhas e perfilhos recuperando assim sua capacidade fotossintética (JOHANSSON, 1993). Com isso pode ocorrer redução ou até paralisação do crescimento das raízes proporcional a intensidade e frequência de desfolha (DONAGHY; FULKERSON, 2002; FRANK, 2007).

A adição de fertilizantes nitrogenados apresentou interferência no crescimento de raízes de forrageiras tropicais como em Panicum maximum (SARMENTO et al., 2008), capim aruana e tanzânia (GIACOMINI et al., 2005). Da mesma forma, Da Cunha et al. (2010) demostraram efeito positivo do uso da irrigação sobre o sistema radical de capim tanzânia. Contudo, há carência de informações sobre o crescimento de raízes em forrageiras temperadas.

Thornton e Millard (1996) demonstraram que o desenvolvimento das raízes pode ocorrer de maneira diferenciada entre espécies vegetais e que a elevada taxa de crescimento que ocorre em algumas espécies vegetais pode refletir no desenvolvimento das raízes. Por isso muitas vezes não é possível realizar extrapolações de uma espécie vegetal para outra. Sendo assim não é possível extrapolar resultados de crescimento de espécies tropicais para espécies temperadas.

Da mesma forma, a mistura de espécies forrageiras, amplamente utilizado como fonte de alimentação animal ou cobertura vegetal no inverno de regiões temperadas, pode ter o crescimento de raízes da comunidade de plantas variável ao longo do período de desenvolvimento destas espécies, uma vez que elas possuem desenvolvimento em tempos diferentes, dentro da mesma estação (PELLEGRINI et al., 2010)

Em misturas de aveia preta e azevém anual existem poucas informações comparando-se simultaneamente os efeitos do pastejo e sua ausência e de doses de adubações de N sobre o crescimento, volume e o diâmetro de raízes, tornando-se importante conhecer o comportamento das raízes destas espécies sob estas condições, pois pode existir uma variação na resposta destas espécies em função dos tratamentos impostos.

Sendo assim, partindo da hipótese de que o pastejo e a adubação nitrogenada podem influenciar o crescimento do sistema radical e assim causar modificações na morfologia das raízes, este trabalho teve por objetivo avaliar o efeito do pastejo e da adubação nitrogenada sobre o desenvolvimento e a morfologia do sistema radical da mistura de aveia preta e azevém anual.

\section{Materiais e Métodos}

O experimento foi realizado na área experimental do Setor de Ciências Agrárias e Ambientais da Universidade Estadual do Centro-Oeste (UNICENTRO), em Guarapuava-PR localizado a $25^{\circ} 33^{\prime}$ Sul e $51^{\circ} 29^{\prime}$ Oeste com altitude média de $1.095 \mathrm{~m}$. O clima da região é classificado conforme Koopen-Geiger como do tipo Cfb (Subtropical úmido temperado). Para caracterizar as condições meteorológicas durante o período experimental foi determinado o balanço hídrico climatológico para a cultura da aveia preta e azevém anual com base nas médias históricas (1960 a 1990) e o balanço hídrico sequencial para a cultura da aveia preta e azevém anual no ano de 2010 utilizando os dados fornecidos pelo INMET (2013) (Figura 1) a partir da metodologia de Thornthwaite e Mather (1955). Na área experimental o solo é classificado como associação Latossolo Bruno distroférrico típico, relevo suave ondulado, substrato de rochas basálticas (EMBRAPA, 2006) de textura argilosa $\left(0,624 \mathrm{~kg} \mathrm{~kg}^{-1}\right.$ de argila, $0,311 \mathrm{~kg} \mathrm{~kg}^{-1}$ de silte e $0,080 \mathrm{~kg} \mathrm{~kg}^{-1} \mathrm{de}$ areia). A análise de solo referente à profundidade de 0 a $15 \mathrm{~cm}$ da área experimental no ano de 2010 demonstrou valores de: $\mathrm{K}=135,32$ $\mathrm{mg} \cdot \mathrm{dm}^{-3}, \mathrm{P}=3,67 \mathrm{mg} \cdot \mathrm{dm}^{-3}, \mathrm{Ca}=3,25 \mathrm{cmol}_{\mathrm{c}} \cdot \mathrm{dm}^{-3}$, $\mathrm{Mg}=2,66 \mathrm{cmol}_{\mathrm{c}} \cdot \mathrm{dm}^{-3}, \mathrm{MO}=40,68 \%, \mathrm{CTC}(\mathrm{pH}$ $7,0)=10,85 \%, \mathrm{~V} \%=56,51 \%$ e pH $\left(\mathrm{CaCl}_{2}\right)=4,79$. 
Nesta área, há quatro anos vem sendo realizada integração lavoura-pecuária com pastejo de ovinos em forrageiras de inverno, aveia preta (Avena strigosa Schreb) e azevém anual (Lolium multiflorum Lam), e lavouras de milho (Zea mays L.) e feijão (Phaseolus vulgaris L.) em rotação de culturas.

Figura 1. Saldo hídrico climatológico e do ano de 2010 para o município de Guarapuava-PR.

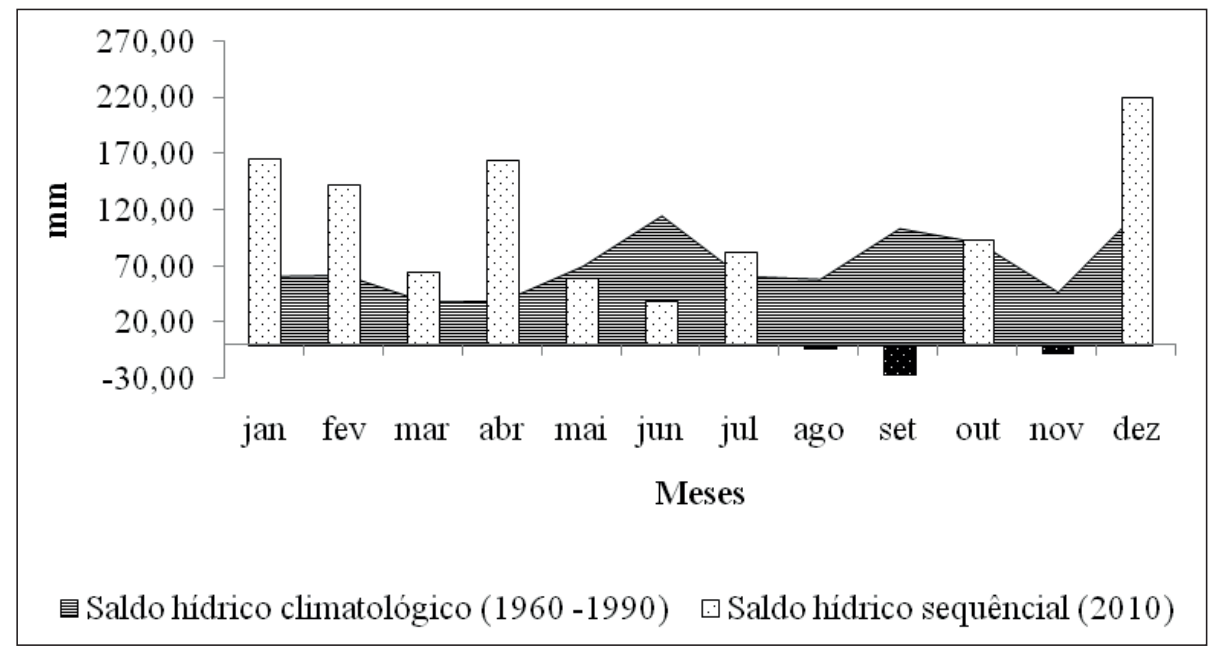

Fonte: Elaboração dos autores.

Foram comparados a utilização da mistura aveia preta com azevém anual como pastagem ou como cobertura de solo e a utilização de dois níveis de adubação nitrogenada 75 e $150 \mathrm{~kg}$ de N.ha ${ }^{-1}$. O delineamento experimental foi de blocos ao acaso, com três repetições, em parcelas sub-subdivididas, onde a presença do pastejo representaram as parcelas, os níveis de nitrogênio as sub parcelas e os períodos de avaliação as sub-subparcelas, totalizando 12 sub parcelas e 48 sub-subparcela. Cada parcela correspondia a um piquete de 0,24 ha nas áreas pastejadas e $96 \mathrm{~m}^{2}$ nas áreas sem pastejo.

A pastagem de inverno foi estabelecida no dia 07/06/2010 em sucessão a cultura do milho por semeadura direta mecanizada com espaçamento entre linhas de $0,17 \mathrm{~m}$, profundidade de semeadura de 1,5 cm, utilizando $60 \mathrm{~kg} \cdot \mathrm{ha}^{-1}$ de semente de aveia preta mais $40 \mathrm{~kg} \cdot \mathrm{ha}^{-1}$ de sementes de azevém anual. A adubação de base foi realizada no momento da semeadura com $50 \mathrm{~kg} \cdot \mathrm{ha}^{-1}$ de $\mathrm{P}_{2} \mathrm{O}_{5}$ e $50 \mathrm{~kg} \cdot \mathrm{ha}^{-1}$ de $\mathrm{K}_{2} \mathrm{O}$. A adubação nitrogenada foi realizada com uréia $(45 \%$ de $\mathrm{N})$ no início do perfilhamento.

O pastejo foi realizado inicialmente por ovelhas gestantes da raça Ile de France e foi finalizado por seus cordeiros nascidos durante o período experimental após desmame com aproximadamente 60 dias de idade. Os animais foram locados na área experimental no dia 05/07/2010 e lá permaneceram até o dia 14/11/2010. O método de utilização da pastagem foi de pastejo contínuo com lotação variável. Foram mantidas três ovelhas e seus respectivos cordeiros como animais testes e número variável de animais reguladores. $\mathrm{O}$ ajuste da lotação foi realizado a cada 14 dias, conforme a técnica "put and take" (MOTT; LUCAS, 1952). A disponibilidade de forragem foi monitorada mediante a avaliação da altura do pasto, que se buscou manter em $15 \mathrm{~cm}$ de altura em todas as unidades experimentais.

As amostragens de raízes foram iniciadas após 30 dias da implantação da pastagem e concomitantemente a entrada dos animais nas áreas pastejadas, no dia 05/07 e após ocorreram 
periodicamente nos dias 09/08 e 13/09 e finalizouse no dia 15/11, após o último dia de utilização da pastagem.

Em cada sub-parcela, foram coletadas três subamostras aleatórias dentro do piquete com pastejo e duas sub-amostras aleatórias nos piquetes sem pastejo. As sub-amostras foram misturadas e compuseram a amostra final de cada sub-parcela.

Para a coleta das amostras foi utilizado o método do cilindro proposto por Da Cunha et al. (2010) modificado, sendo esse mais indicado por não necessitar abrir trincheiras. Para este experimento foi utilizado um cilindro com $10 \mathrm{~cm}$ de diâmetro, $20 \mathrm{~cm}$ de profundidade totalizando $1,57 \mathrm{dm}^{3}$ de volume, posicionado no meio da linha de semeadura e cravado com auxilio de uma marreta até seu completo preenchimento.

A parte aérea correspondente à área da amostra $\left(78,54 \mathrm{~cm}^{2}\right)$ foi cortada rente ao solo e acondicionada em saco plástico identificado para estimativa da massa seca da parte aérea, após secagem em estufa de circulação forçada de ar, à temperatura de $60^{\circ} \mathrm{C}$ até atingir peso constante, em seguida foram pesadas em balança de $0,01 \mathrm{~g}$ de precisão estimando-se a sua massa seca em Mg.ha- ${ }^{-1}$ de MS.

O conteúdo do cilindro, solo mais raízes, foi retirado e acondicionado em saco plástico identificado e levados ao laboratório para limpeza e mensurações. Nessa limpeza, as amostras foram colocadas em baldes e submergidas durante 12 horas em uma solução $0,01 \mathrm{~N}$ de $\mathrm{NaOH}$ para dispersão das argilas. Em seguida foram lavadas utilizando torneira e um conjunto de peneiras com malha de $0,50 \mathrm{~mm}$ e $0,25 \mathrm{~mm}$ conforme Ido (2003). Depois de removidas todas as impurezas as raízes permaneceram armazenadas em etanol 50\% (BOHM, 1979) até as mensurações.

Os parâmetros das raízes foram analisados com o sistema de imagens Win/MacRizho versão 4.1 (RÉGENT INSTRUMENTS, 1999ab) com resolução média de 300 dpi, extrapolando-se as mensurações com a unidade de área hectare. Foram determinados: o comprimento (C - km.ha $\left.{ }^{-1}\right)$, a área da superfície $\left(\mathrm{A}-\mathrm{m}^{2} \cdot \mathrm{ha}^{-1}\right)$, o diâmetro médio (D $\mathrm{mm})$ e o volume $\left(\mathrm{V}-\mathrm{m}^{3} \cdot \mathrm{ha}^{-1}\right)$. A massa seca das raízes $\left(\mathrm{Mg} \cdot \mathrm{ha}^{-1}\right)$ foi determinada em balança de $0,01 \mathrm{~g}$ de precisão após secagem à temperatura de $60^{\circ} \mathrm{C}$ até que atingissem peso constante. A partir das variáveis obtidas foi possível estimar: a massa específica do tecido radical $\left(\mathrm{kg} . \mathrm{m}^{-3}\right)$ através da razão entre a massa e o volume de raiz e a relação parte aérea:raiz através da razão entre a massa da parte aérea pela massa de raiz.

Considerando os 3 períodos: período 1 (05/07/2010 a 09/08/2010), período 2 (09/08/2010 a 13/09/2010) e período 3 (13/09/2010 a 15/11/2010), foi calculada a taxa de crescimento relativo de raiz diário (TCRR - km.ha ${ }^{-1} \cdot$ dia $^{-1}$ ) a partir da Equação 1 e a taxa de expansão relativa de raiz diária (TERR $-\mathrm{cm}^{2} \cdot \mathrm{ha}^{-1} \cdot \mathrm{dia}^{-1}$ ) a partir da Equação 2. Foi proposto o crescimento relativo e a taxa de expansão relativa, pois a metodologia utilizada, não permite determinar a redução do comprimento e da área em função da morte das raízes ocorrida dentro dos períodos considerados. Também foi estimada a taxa de acumulo de matéria seca diária (TAMS - kg.ha-1. dia $^{-1}$ ) a partir da Equação 3 .

$T C R R=\frac{c_{n}-c_{n-1}}{d}$ onde:

TCRR $=$ taxa de crescimento relativo de raiz $\left(\mathrm{km} \cdot \mathrm{ha}^{-1} \cdot \mathrm{dia}^{-1}\right)$

$\mathrm{C}_{\mathrm{n}}=$ comprimento das raízes no dia da avaliação $\left(\mathrm{km} \cdot \mathrm{ha}^{-1}\right)$

$\mathrm{C}_{\mathrm{n}-1}=$ comprimento das raízes no dia da avaliação anterior $\left(\mathrm{km} \cdot \mathrm{ha}^{-1}\right)$

$\mathrm{d}=$ numero de dias entre duas avaliações

$T E R R=\frac{A_{n}-A_{n-1}}{d}$ onde:

TERR $=$ taxa de expansão relativa de raiz diária $\left(\mathrm{cm}^{2} \cdot \mathrm{ha}^{-1} \cdot \mathrm{dia}^{-1}\right)$ 
$\mathrm{A}_{\mathrm{n}}=$ área da superfície das raízes no dia da avaliação $\left(\mathrm{cm}^{2} \cdot \mathrm{ha}^{-1}\right)$

$\mathrm{A}_{\mathrm{n}-1}=$ área da superfície das raízes no dia da avaliação anterior $\left(\mathrm{cm}^{2} \cdot \mathrm{ha}^{-1}\right)$

$\mathrm{d}=$ numero de dias entre duas avaliações

TAMS $=\frac{M S_{n}-M S_{n-1}}{d}$ onde:

TAMS = taxa de acúmulo de matéria seca radical diária $\left(\mathrm{kg} \cdot \mathrm{ha}^{-1} \cdot \mathrm{dia}^{-1}\right)$

$\mathrm{MS}_{\mathrm{n}}=$ matéria seca nas raízes no dia da avaliação (kg.ha-1)

$\mathrm{MS}_{\mathrm{n}-1}=$ matéria seca nas raízes no dia da avaliação anterior (kg.ha-1)

$\mathrm{d}=$ numero de dias entre duas avaliações

Em avaliação da composição botânica da parte aérea da pastagem realizada durante o período 1 (27/07/2010), a aveia preta correspondia a $82,8 \%$ da biomassa vegetal enquanto que o azevém correspondia a $13,5 \%$ e material senescente apenas $3,7 \%$. Por outro lado, na avaliação da composição botânica realizada dia no período 3 (02/11/2010), a aveia passou a compor $48 \%$, o azevém ocupava $19,7 \%$ e o material senescente $32,3 \%$.

As análises estatísticas foram realizadas utilizando o software estatístico SPSS Statistics 17.0. Foi realizada análise de variância e o teste de comparação de médias pelo Teste de Tukey considerando significância de $5 \%$ através do procedimento GLM (General Linear Model) utilizando o modelo estatístico:

$\mathrm{Y}_{\mathrm{ijk}}=\mu+$ Bloco + Pastejo $+\mathrm{E}_{\text {parcela }}+$ Dose de $\mathrm{N}+$ Pastejo x Dose de $\mathrm{N}+\mathrm{E}_{\text {sub-parcela }}+$ Período + Pastejo $\mathrm{x}$ Período + Dose de $\mathrm{N}$ x Período + Pastejo x Dose de $\mathrm{N} x$ Período $+\mathrm{E}_{\text {sub-sub-parcela. }}$
Também foi realizada análise de regressão simples em função dos dias após o início do pastejo (DAIP), determinando as equações de ajuste e $\mathrm{R}^{2}$.

\section{Resultados e Discussão}

Em 2010, durante o inverno e nas semanas iniciais da primavera as chuvas foram escassas (Figura 1), o que deve ter afetado negativamente o crescimento das plantas.

As condições meteorológicas, principalmente a disponibilidade hídrica, podem ter grandes influencias sobre o crescimento e desenvolvimento do sistema radical (GILL; JACKSON, 2000; GIACOMINI et al., 2005; DA CUNHA et al., 2010) uma vez que nos locais onde se concentram as raízes ocorre maior movimentação da água e mais rápido esgotamento (HUNT; MORGAN; READ, 1998).

Além destas condições, as fases do ciclo das culturas forrageiras utilizadas pode ter interferência no comportamento das taxas de desenvolvimento radical da pastagem. Floss (2011) argumenta que durante a fase vegetativa grande parte dos fotoassimilados produzidos pelas folhas e não utilizados para a elongação de novas folhas é translocado para as raízes a fim de armazená-los.

Os resultados apresentados na Tabela 1 referem-se à taxa de crescimento relativo de raiz (TCRR) das raízes nos três períodos avaliados. A TCRR acompanha o crescimento das culturas utilizadas na pastagem. No primeiro período a disponibilidade de água foi adequada (Figura 1), considerando que neste momento a aveia preta ocupava maior porção da paisagem e apresentava maior desenvolvimento vegetativo, ocorreu maior $(\mathrm{p}<0,001)$ TCRR do sistema radical das plantas. 
Tabela 1. Médias estimadas, significância e desvio padrão de taxa de crescimento relativo de raiz (TCRR - $\left.k m \cdot h a^{-1} \cdot d^{-1}\right)$ da mistura de aveia preta mais azevém anual com e sem pastejo e doses de nitrogênio (N). Guarapuava, 2010.

\begin{tabular}{lcccc}
\hline & Período 1 (05/07 a 09/08) & Período 2 (10/08 a 13/09) & Período 3 (14/09 a 15/11) & Média \\
\hline Formas de utilização & & & & \\
Com pastejo & $181,57^{\mathrm{ns}}$ & $31,63^{\mathrm{ns}}$ & $90,40^{\mathrm{ns}}$ & $101,20^{\mathrm{ns}}$ \\
Sem pastejo & 175,59 & 7,41 & 114,76 & 99,25 \\
\hline Dose de nitrogênio & & & & \\
$75 \mathrm{~N}$ & $186,5^{\mathrm{ns}}$ & $-7,37^{\mathrm{ns}}$ & $123,54^{\mathrm{ns}}$ & $100,89^{\mathrm{ns}}$ \\
$150 \mathrm{~N}$ & 170,65 & 46,42 & 81,62 & 99,56 \\
\hline$*_{\mathrm{s}}$ & 46,45 & 57,22 & 83,05 & \\
Média & $178,58^{\mathrm{A}}$ & $19,52^{\mathrm{C}}$ & $102,58^{\mathrm{B}}$ & \\
\hline
\end{tabular}

Medidas seguidas de mesma letra maiúscula não diferem significativamente entre si pelo teste de Tukey ao nível de $5 \%$ de probabilidade em relação aos períodos.

*s - desvio padrão da média.

Fonte: Elaboração dos autores.

Por outro lado, no segundo período se iniciou o déficit hídrico, que, em conjunto com o aumento da taxa de senescência das plantas promoveu a redução do ciclo total de crescimento e de produção. Isto pode ser verificado a partir da grande quantidade de material senescente nos dados de composição botânica da segunda avaliação. Este fator foi determinante na redução $(\mathrm{p}<0,001)$ da TCR.

Apesar de não ter apresentado interação significativa $(p=0,678)$, durante este período, nas áreas onde houve o pastejo, a redução da TCRR das plantas foi menos expressiva, isso provavelmente deve-se ao fato do pastejo reduzir a quantidade de massa de parte aérea de plantas acima do solo, sobretudo de folhas, onde se concentram a maior atividade metabólica e que podem afetar a quantidade de carboidratos que podem ser disponibilizados para as raízes, aumentando o comprimento das raízes (Tabela 1) conferindo melhores condições para absorção de água, prolongando o estagio vegetativo das culturas (TRACY; ZHANG, 2008), mesmo em situação de estresse hídrico.

No terceiro período a TCR voltou a aumentar provavelmente em função das plantas de azevém que aumentaram sua proporção na paisagem.

Para as doses de $\mathrm{N}$ utilizadas, não houve diferenças significativas $(p>0,05)$. Entretanto, no segundo período de avaliação as plantas com menor dose de $\mathrm{N}$ reduziram o comprimento das raízes indicado pelo valor negativo obtido. Por outro lado, nos pastos adubados com $150 \mathrm{~kg}$ de $\mathrm{N} \mathrm{ha}^{-1}$ não mostraram paralisação no crescimento, indicando que as raízes das plantas com bom suprimento de $\mathrm{N}$ tendem a permanecer crescendo mesmo em situação de estresse hídrico.

Nos períodos onde a oferta de água era suficiente, as plantas que receberam a menor dose de $\mathrm{N}$ tenderam a ter maior crescimento radical. Isso pode ter ocorrido em função do aumento da dose de $\mathrm{N}$ aplicada, aumentar o crescimento da parte aérea e com isso ocorrer à redução do crescimento das raízes devido à translocação de substâncias de reserva desta porção para parte aérea da planta (JOHANSSON, 1993).

Lemaire (1997) discute que em situação de baixa disponibilidade de $\mathrm{N}$, a atividade meristemática da parte aérea é reduzida, sendo assim as plantas alocam maior quantidade de fotoassimilados para o crescimento do sistema radical afim das raízes poderem explorar maior proporção de solo em busca de nutrientes. Bosemark (1954), também com baixas doses de $\mathrm{N}$, verificou raízes mais longas se comparadas as doses mais altas deste nutriente. 
Os valores médios da taxa de expansão relativa de raiz (TERR) das raízes nos três períodos avaliados na presença e ausência do pastejo e com as doses de adubação nitrogenada são apresentados na Tabela 2.

Tabela 2. Médias estimadas, significância e desvio padrão de taxa de expansão relativa de raiz (TERR $\left.-\mathrm{cm}^{2} \cdot \mathrm{ha}^{-1} \cdot \mathrm{d}^{-1}\right)$ da mistura de aveia preta mais azevém anual com e sem pastejo e com doses de nitrogênio (N). Guarapuava, 2010.

\begin{tabular}{lcccc}
\hline & Período 1 (05/07 a 09/08) & Período 2 (10/08 a 13/09) & Período 3 (14/09 a 15/11) & Média \\
\hline Formas de utilização & & & & \\
Com pastejo & $596,89^{\mathrm{ns}}$ & $-88,99^{\mathrm{ns}}$ & $198,89^{\mathrm{ns}}$ & $235,60^{\mathrm{ns}}$ \\
Sem pastejo & 516,85 & -86 & 192,87 & 207,91 \\
\hline Dose de nitrogênio & & & & \\
$75 \mathrm{~N}$ & $568,77^{\mathrm{ns}}$ & $-148,06^{\mathrm{ns}}$ & $234,57^{\mathrm{ns}}$ & $218,43^{\mathrm{ns}}$ \\
$150 \mathrm{~N}$ & 544,96 & $-26,93$ & 157,18 & 225,07 \\
\hline$*_{S}$ & 127,86 & 138,31 & 114,62 & \\
Média & $556,86^{\mathrm{A}}$ & $-87,50^{\mathrm{C}}$ & $195,88^{\mathrm{B}}$ & \\
\hline
\end{tabular}

Medidas seguidas de mesma letra maiúscula não diferem significativamente entre si pelo teste de Tukey ao nível de $5 \%$ de probabilidade em relação aos períodos.

*s - desvio padrão da média.

Fonte: Elaboração dos autores.

Os resultados obtidos indicam redução $(\mathrm{p}<0,001)$ da TERR no segundo período, assumindo valores negativos. Nesta amostragem, as plantas de aveia preta estavam finalizando seu ciclo de desenvolvimento e aliado às condições de estresse hídrico em que as plantas estavam submetidas, estas tenderam a manter as raízes mais finas (Figura 3a) uma vez que essas possuem como função primária a absorção de água e nutrientes (EISSENSTAT; YANAI, 1997) e utiliza as reservas das raízes mais grossas a fim de manter o suprimento energético para manutenção da parte aérea (EISSENSTAT et al., 2000) e neste caso, também da inflorescência.

Quando as plantas se apresentam em estágio vegetativo, as taxas de fotossíntese são elevadas, permitindo que os fotoassimilados possam ser translocados para as folhas em expansão (LAWLOR, 2002), e o excesso para as raízes na forma de reservas orgânicas (LEMAIRE; AGNUSDEI, 2000). Por outro lado, Eissenstat e Yanai (1997) afirmaram que quando a planta passa ao estágio reprodutivo, as flores, e depois as sementes passam a requerer a maior parte dos fotoassimilados, principalmente para plantas anuais que não necessitam manter reservas para que haja o rebrote.

Observando a TERR em função das doses de nitrogênio, percebe-se que ocorreu situação semelhante à taxa de crescimento onde as plantas que receberam a menor dose de nitrogênio tenderam a aumentar a TERR.

Situação semelhante é observada na Tabela 3, que apresenta os resultados da taxa de acumulo de matéria seca (TAMS) das raízes nos três períodos avaliados com ou sem pastejo e com as doses de nitrogênio utilizadas. 
Tabela 3. Médias estimadas, significância e desvio padrão de taxa de acumulo de MS (TAMS - $\mathrm{kg} \cdot \mathrm{ha}^{-1} \cdot \mathrm{d}^{-1}$ ) de pastagem de aveia preta mais azevém anual com e sem pastejo. Guarapuava, 2010.

\begin{tabular}{lcccc}
\hline & Período 1 (05/07 a 09/08) & Período 2 (10/08 a 13/09) & Período 3 (14/09 a 15/11) & Média \\
\hline Formas de utilização & & & & \\
Com pastejo & $5,53^{\mathrm{ns}}$ & $-0,26^{\mathrm{ns}}$ & $2,45^{\mathrm{ns}}$ & $2,57^{\mathrm{ns}}$ \\
Sem pastejo & 4,39 & 1,41 & 3,37 & 3,06 \\
\hline Dose de nitrogênio & & & & \\
$75 \mathrm{~N}$ & $4,77^{\mathrm{ns}}$ & $0,80^{\mathrm{ns}}$ & $2,47^{\mathrm{ns}}$ & $2,68^{\mathrm{ns}}$ \\
$150 \mathrm{~N}$ & 5,15 & 0,33 & 3,36 & 2,95 \\
\hline$*_{S}$ & 1,42 & 1,59 & 1,91 & \\
Média & $4,96^{\mathrm{A}}$ & $0,57^{\mathrm{C}}$ & $2,91^{\mathrm{B}}$ & \\
\hline
\end{tabular}

Medidas seguidas de mesma letra maiúscula não diferem significativamente entre si pelo teste de Tukey ao nível de $5 \%$ de probabilidade em relação aos períodos

*s - desvio padrão da média.

Fonte: Elaboração dos autores.

No segundo período a TAMS de raízes foi menor na situação de pastejo ( $\mathrm{p}=0,095)$, concordando com os resultados obtidos por Mackie-Dawson (1999) avaliando Lolium perenne cultivados em vasos e desfolha manual, encontraram redução na massa de raízes das plantas sob o estresse da desfolha. Arredondo e Johnson (1999) relataram redução na biomassa e comprimento de raízes com pastejo em função das alterações na demografia de raízes ocasionada devido a desfolha.

A TAMS foi menor para a dose de $75 \mathrm{~kg} \mathrm{~N} \cdot \mathrm{ha}^{-1}$, exceto para o segundo período. Como no presente experimento, Baligar, Fageria e Elrashidi (1998) percebeu menor influencia da massa de raízes que o comprimento em função das doses de $\mathrm{N}$ em trigo (Triticum aestivum L.). Por outro lado, os resultados aqui obtidos discordam dos resultados obtidos por Sarmento et al. (2008) que estudando plantas perenes tropicais de Panicum maximum, perceberam aumento linear de comprimento da raiz com dose de nitrogênio até $150 \mathrm{~kg} \cdot \mathrm{ha}^{-1}$.

O mesmo foi encontrado por Giacomini et al. (2005) comparando o crescimento e a superfície das raízes de plantas perenes de Panicum maximum cv. aruana e cv. tanzânia com doses de 150 e 300 $\mathrm{kg}$ de N.ha ${ }^{-1}$, encontraram diferença para as duas variáveis estudadas apenas para a cv. Tanzânia onde na dose $300 \mathrm{~kg} \mathrm{~N} \cdot \mathrm{ha}^{-1}$ o crescimento e a expansão radical foram maiores. Provavelmente as diferenças dos resultados citados em relação a este trabalho podem ter ocorrido em função das espécies utilizadas naqueles experimentos serem plantas tropicais e perenes que apresentam maiores taxas de crescimento da pastagem.

Snaydon (1991) conclui que para espécies tropicais perenes de metabolismo fotossintético $\mathrm{C}_{4}$ as maiores taxas de crescimento devem-se a maior taxa de fotossíntese realizada por estas em comparação a plantas $\mathrm{C}_{3}$. Com isso, provavelmente em função da menor taxa de crescimento e as espécies estudadas neste experimento serem anuais não foi observada diferenças entre as doses de $\mathrm{N}$ utilizadas como apresentaram outros trabalhos.

As TCR e TER permitiram que as características morfológicas de comprimento, área da superfície, diâmetro e volume radical das plantas fosse alterada.

O comprimento radical médio durante o período experimental para o sistema com pastejo foi de $14188,98 \mathrm{~km} \cdot \mathrm{ha}^{-1}$ sendo superior $(\mathrm{p}=0,001)$ ao sistema sem pastejo que apresentou 12154,20 $\mathrm{km} \cdot \mathrm{ha}^{-1}$ de comprimento de raízes. Da mesma forma, o diâmetro médio de raiz foi diferente para os sistemas $(\mathrm{p}=0,17)$ onde o sistema pastejado 
apresentou diâmetro médio das raízes de $0,88 \mathrm{~mm}$ enquanto que o sistema sem pastejo apresentou $0,85 \mathrm{~mm}$.

Ryle (1970) descreveu a dinâmica de fotoassimilados em pastagem de Lolium perene L. e Lolium temulentum L. afirmando que as folhas posicionadas com inserção mais baixa são fonte de assimilados predominantemente para as raízes e perfilhos enquanto aquelas de nível de inserção mais alta exportaram para o meristema caulinar. Sendo assim, quando o pastejo é realizado de forma moderada, apenas as folhas mais novas são removidas enquanto que as mais velhas permanecem garantindo o aporte de fotoassimilados para raiz. Todavia, quando o pastejo é realizado intensamente, tanto folhas superiores quanto inferiores são removidas suspendendo a translocação de fotoassimilados para as raízes.

Neste experimento, houve a preocupação de manter um índice de área foliar residual que permitisse a rebrota utilizando os fotoassimilados sintetizados pelas folhas. Desta forma, esses resultados indicam que a remoção de parte das folhas estimula a planta a promover o desenvolvimento radical, provavelmente a fim de maximizar a absorção de água e nutrientes e com isso recuperar seu aparato fotossintético mais rapidamente.

Arredondo e Johnson (1999) demostraram que para gramíneas perenes em situação de deficiência hídrica o pastejo pode reduzir a quantidade de biomassa e o comprimento das raízes em detrimento da recuperação das folhas e perfilhos.
Desta forma, através das análises de regressão das características morfológicas estudadas percebese que existe grande variação ao longo do ciclo de desenvolvimento das culturas e das condições meteorológicas impostas ao ambiente onde as plantas se encontram. Isto pode ser verificado nas Figuras 2, 3, 4 e 5 que evidenciam as variações morfológicas das raízes da pastagem ao longo do seu período de utilização.

Curvas que descrevem à variação do comprimento (Figura 2a) e do diâmetro das raízes (Figura 2b) durante o período experimental, independente da ocorrência do pastejo, apresentaram comportamento semelhante em relação aos sistemas de utilização.

Até o $35^{\circ}$ dia após o início do pastejo o comprimento aumentou. Isto provavelmente ocorreu devido ao estagio de desenvolvimento em que a aveia preta se encontrava e da disponibilidade hídrica estar adequada, sendo assim tanto a parte aérea quanto o sistema radical apresentaram elevada taxa de crescimento.

Van Soest (1994) relata que durante o período vegetativo, quando a síntese de fotoassimilados é maior que sua utilização pela parte aérea, estes são armazenados em órgãos de reserva como base do colmo e raízes, aumentando seu crescimento. Por outro lado, segundo o mesmo autor, durante o período reprodutivo ocorre remobilização de fotoassimilados para flor e consequentemente para as sementes, corroborando com os resultados apresentados neste trabalho. 
Figura 2. Relação entre o comprimento radical (a) e diâmetro médio radical (b) para o sistema com pastejo (CP) e sem pastejo (SP) nos dias após o início do pastejo (DAIP). Guarapuava, 2010.

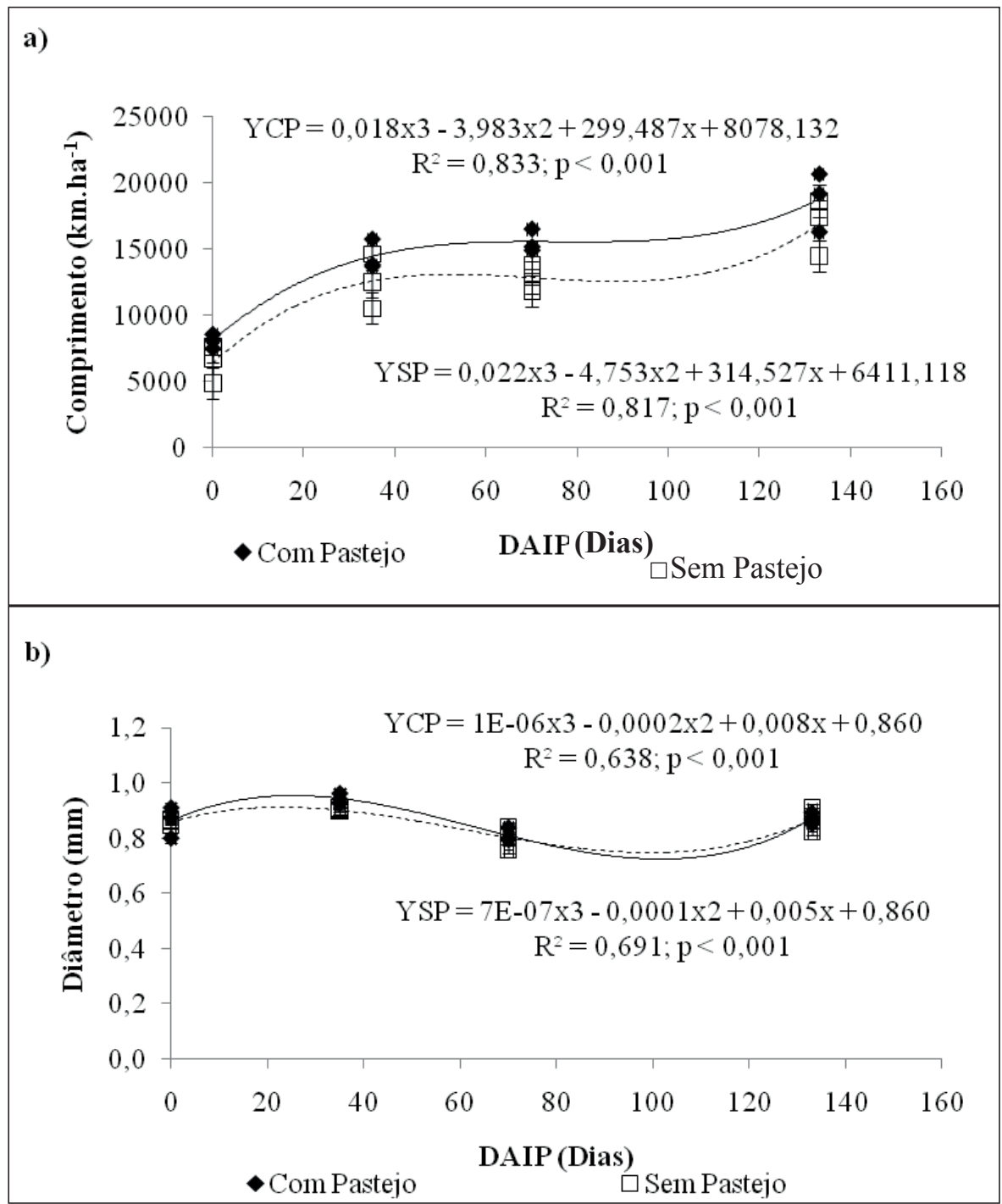

Fonte: Elaboração dos autores.

Após este período inicial as plantas tenderam a estabilizar o comprimento das raízes, e seu diâmetro tendeu a reduzir. Neste momento se iniciou o período de deficiência hídrica (Figura 2), e esta condição provavelmente levou as plantas de aveia preta ao estágio reprodutivo e senescência; tão logo as raízes reduziram seu alongamento uma vez que nesta fase a inflorescência passa a demandar grande parte da energia que era utilizada para o crescimento de outras partes da planta principalmente para espécies anuais, como relatam Eissenstat e Yanai (1997).
A redução do diâmetro médio pode ter ocorrido provavelmente ao fato de que as raízes mais finas apresentam maior absorção de água e nutrientes, (EISSENSTAT; YANAI, 1997) garantindo o suprimento de água para as plantas na fase reprodutiva em função da baixa disponibilidade de água. Por outro lado, parte das reservas armazenadas nas raízes mais grossas podem ter sido remobilizadas para a parte aérea e principalmente para inflorescência (EISSENSTAT et al., 2000), fazendo com que estas raízes morressem. 
No período final, com a senescência das plantas de aveia preta e o aumento da disponibilidade de água, aumentou a proporção de azevém anual na paisagem, uma vez que este, nas condições ambientas do local onde o experimento foi desenvolvido, possui hábito hiberno-primaveril (PELLEGRINI et al., 2010) com grande parte do seu desenvolvimento a partir de setembro. Sendo assim, em função do crescimento vegetativo do azevém anual, as raízes voltaram a crescer em comprimento e espessura, aumentando o diâmetro médio radical.
Houve diferença para área da superfície média $(\mathrm{p}<0,001)$ e para o volume radical médio $(p<0,001)$ entre os sistemas de utilização durante o período experimental. Para o sistema com pastejo á área foi de $39132,76 \mathrm{~m}^{2}$.ha-1 e $32493,58 \mathrm{~m}^{2} . \mathrm{ha}^{-1}$ para o sistema sem pastejo. E o volume de raízes na presença do pastejo foi de $8,68 \mathrm{~m}^{3}$.ha ${ }^{-1}$ e 6,96 $\mathrm{m}^{3} \cdot \mathrm{ha}^{-1}$ na ausência do pastejo.

Através da Figura 3a descreve o comportamento da área da superfície radical e a Figura $3 b$ descreve o comportamento do volume ocupado pelas raízes durante o período de utilização da pastagem.

Figura 3. Relação entre a área da superfície radicular (a) e volume radicular (b) para o sistema com pastejo (CP) e sem pastejo (SP) nos dias após o início do pastejo (DAIP). Guarapuava, 2010.

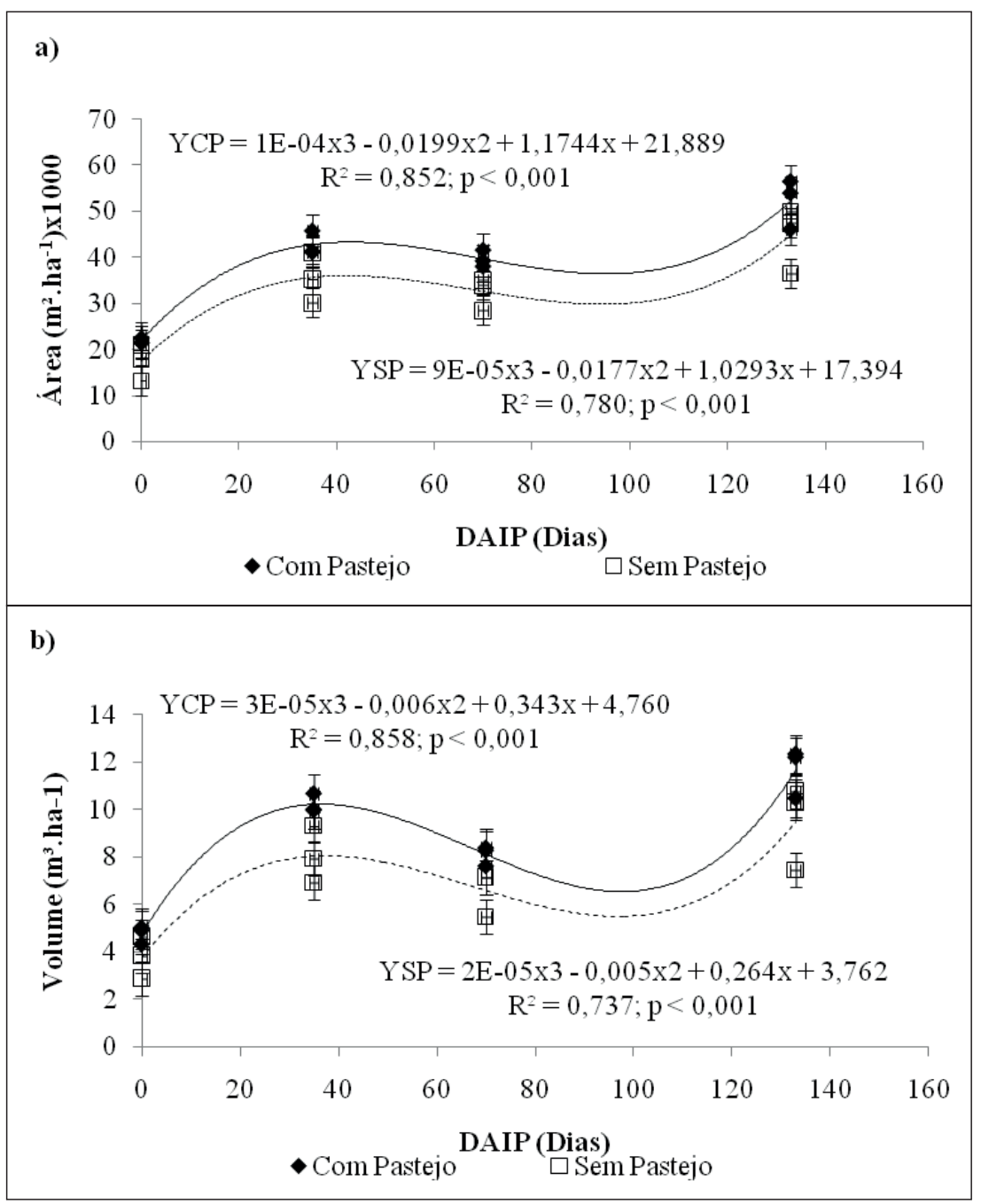

Fonte: Elaboração dos autores. 
O comportamento da área superficial e do volume radical apresenta-se semelhantes ao comprimento e diâmetro (Figura 2a e 2b), indicando que essas variáveis se relacionam diretamente. Sendo assim, a variação da área da superfície e do volume radical, observadas durante os dias de avaliação são reflexo das variações ocorridas com o comprimento e diâmetro radical, uma vez que o volume de raízes corresponde ao produto entre o comprimento e o diâmetro.

A massa seca média da parte aérea na área sem pastejo foi de $2748 \mathrm{~kg} \cdot \mathrm{ha}^{-1}$ de MS enquanto que nas áreas com pastejo foi de $1468 \mathrm{~kg} \cdot \mathrm{ha}^{-1}$ de MS. Não houve diferença significativa $(\mathrm{p}=0,111)$ entre a massa seca de raízes de plantas pastejadas $\left(0,35 \mathrm{Mg} \cdot \mathrm{ha}^{-1}\right)$ em relação às plantas não pastejadas $\left(0,32 \mathrm{Mg} \cdot \mathrm{ha}^{-1}\right)$.

Resultado diferente foi encontrado por MackieDawson (1999) em azevém perene cortado manualmente a $4 \mathrm{~cm}$ de altura. Nesta condição a massa radical foi reduzida em função da remobilização de reservas para recuperação da parte aérea. Cecato et al. (2001) concordam afirmando que a remoção da parte aérea de forma intensa causa prejuízos ao desenvolvimento do sistema radical.

Neste trabalho procurou-se controlar a altura da pastagem a fim de o rebrote da pastagem pudesse ser realizado a partir dos fotoassimilados produzidos a partir das folhas remanescentes do pastejo. Isso pode ser verificado através da Figura 4a, que apresenta o comportamento da massa seca da parte aérea ao longo do período experimental, Durante todo o período a massa seca permaneceu acima de $1000 \mathrm{~kg} \cdot \mathrm{ha}^{-1}$.

Na Figura 4 são apresentados as curvas que descrevem o comportamento da massa seca da parte aérea (a) e das raízes (b), nos dias após o início do pastejo.
A massa das raízes das plantas não pastejadas apresentaram comportamento ascendente durante todo o período de avaliações, ao contrário das plantas pastejadas que reduziu a massa no momento em que a quantidade de material senescente era elevado, caracterizando a senescência das plantas de aveia preta. Quando é realizado o pastejo a remoção das folhas pode reduzir a quantidade de carbono assimilado. Sendo assim, a assimilação realizada pode não ter sido suficiente para suprir as demandas da inflorescência ocorrendo remobilização de carbono das raízes para parte aérea. Isto indica que provavelmente em situação de pastejo, quando a cultura da aveia preta passou para o estágio reprodutivo, a inflorescência passou a ser dreno de fotoassimilados diminuindo o acúmulo de carbono na raiz, podendo haver necessidade de remobilizar reservas do sistema radical para a inflorescência.

Por outro lado, quando não houve pastejo, as folhas foram mantidas durante todo ciclo da cultura. Nesta condição, provavelmente o suprimento de fotoassimilados para inflorescência a partir das folhas era mantido sem necessidade de remobilizar as reservas radicais.

Esta situação, ainda pode ser explicada pelas variações ocorridas na massa específica das raízes (Figura 5a). Esta característica representa a massa correspondente a um volume de raiz que ela ocupa, sendo assim ela pode ser associada ao acúmulo de reservas nas raízes. Durante o estágio vegetativo da aveia preta e boa disponibilidade hídrica, independente da ocorrência do pastejo, a massa específica das raízes tendeu-se manter constante. Quando ocorreu o estresse hídrico e a aveia preta passou a reprodução e senescência, ocorreu aumento mais acentuado da massa específica nas plantas não pastejadas, uma vez que essas acumulavam mais reservas nas raízes. 
Figura 4. Relação entre a massa seca da parte aérea (a) e massa seca radicular (b) para o sistema com pastejo (CP) e sem pastejo (SP) nos dias após o início do pastejo (DAIP). Guarapuava, 2010.

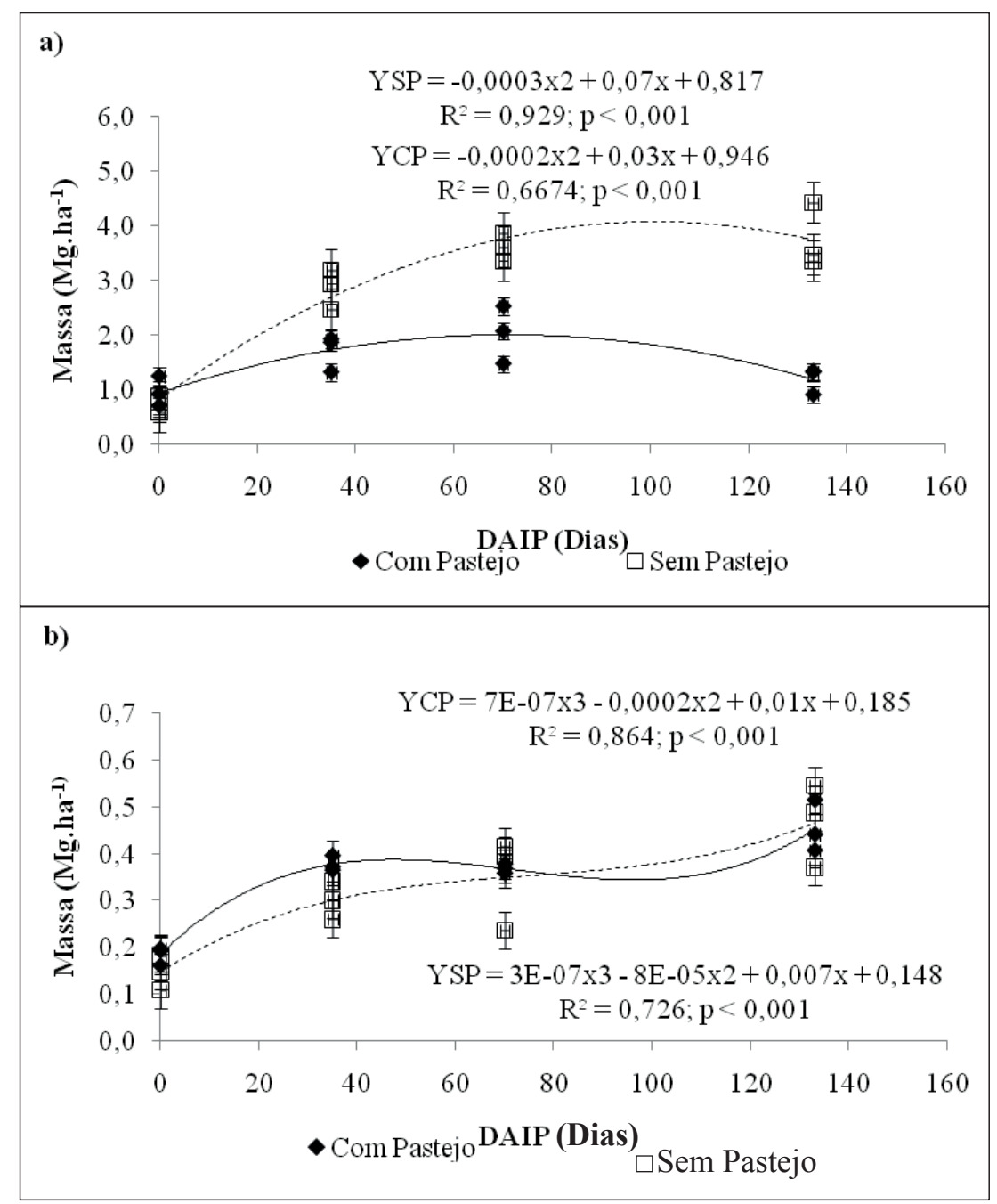

Fonte: Elaboração dos autores.

Em contrapartida, em situação de pastejo provavelmente quando houve o estresse hídrico a plantas, em função da baixa disponibilidade hídrica reduziram a quantidade de carbono assimilado necessitando assim, remobilizar parte das reservas das raízes para a parte aérea e com isso o aumento da massa específica das raízes para essas plantas foi menos pronunciado.

Isto pode ser explicado pela manutenção de raízes mais finas (Figura 2 b) que apresentam menor massa específica. No sistema com pastejo a massa específica média foi de 40,21 kg.m-3, sendo superior $(p=0,001)$ a apresentada pelo sistema sem pastejo que foi de $44,70 \mathrm{~kg} \cdot \mathrm{m}^{-3}$. Isto indica que apesar de ter ocorrido uma possível remobilização de reservas de raízes mais grossa para a parte aérea, existe uma compensação por parte da planta aumentando o comprimento com raízes mais finas.

Isto confirma a afirmação de Arredondo e Johnson (1999) que as plantas ajustam seu desenvolvimento em função do meio em que se desenvolvem. Complementando, Ryser (1996) atribui menor longevidade a raízes que possuem menor massa específica, indicando maior surgimento de novas raízes no sistema com pastejo. 
Figura 5. Relação entre a massa específica radicular (a) e relação parte aérea:raiz (b) para o sistema com pastejo (CP) e sem pastejo (SP) nos dias após o início do pastejo (DAIP). Guarapuava, 2010.

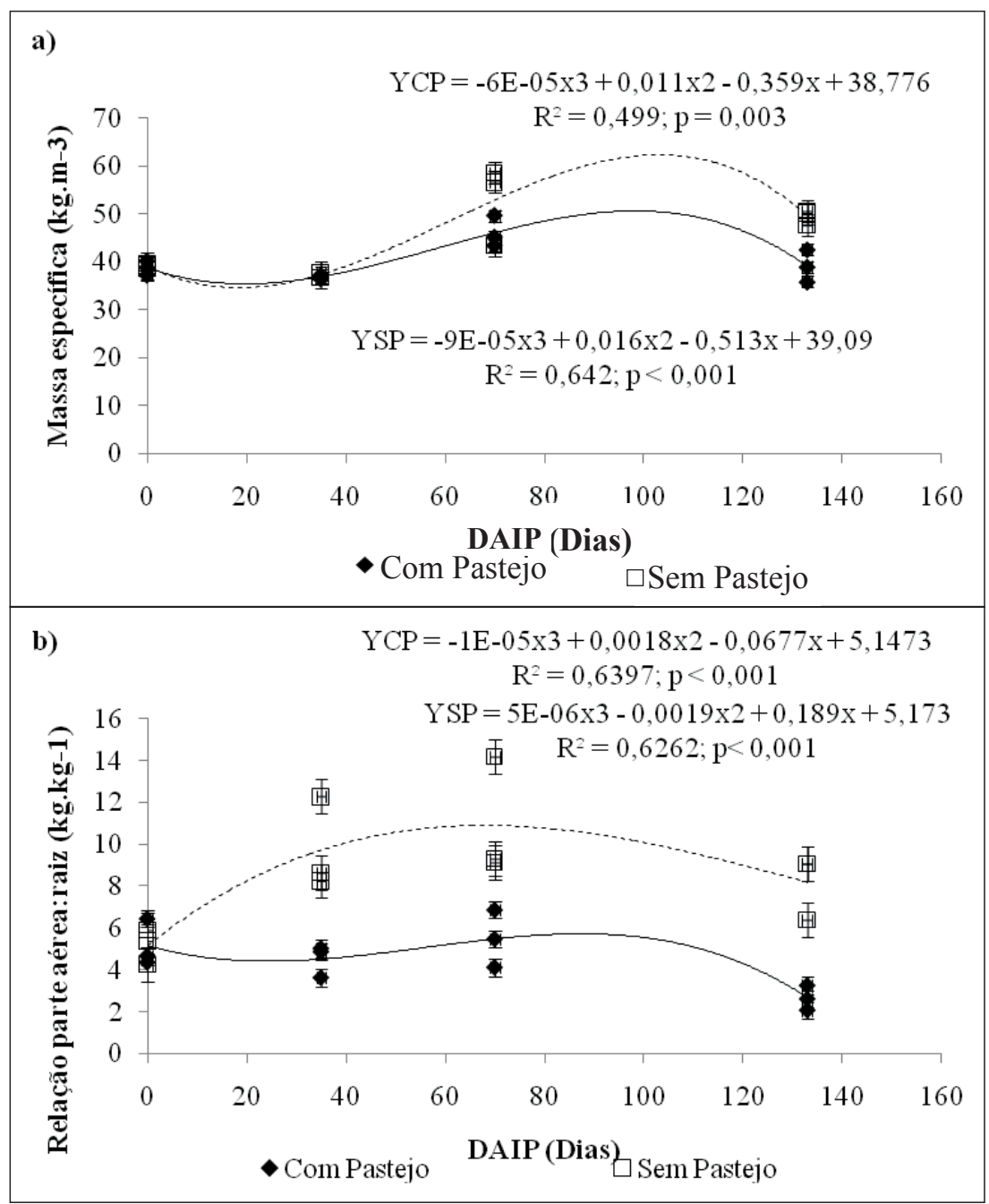

Fonte: Elaboração dos autores.

A relação parte aérea:raiz média do sistema não pastejado foi de $37,14 \mathrm{~kg} \cdot \mathrm{kg}^{-1}$, e foi superior $(\mathrm{p}<0,001)$ que o sistema com pastejo $\left(17,93 \mathrm{~kg} \cdot \mathrm{ha}^{-1}\right)$. Isto pode ser atribuída à manutenção das folhas na própria planta, ao contrário do sistema com pastejo em que as folhas são constantemente retiradas pelo processo de pastejo. Sendo assim, o pastejo mantem as quantidades de biomassa da parte aérea em relação a raiz mais equilibradas ao longo do período utilização. Isto pode ser verificado pela curva que descreve o comportamento da relação parte aérea:raiz ao longo do período de utilização (Figura 5b)
Coupland (1979) encontrou valores de relação parte aérea:raiz que variaram de 2:1 a 13:1 em forrageiras temperadas, por outro lado, em forrageiras tropicais os valores são menores, encontrando-se entre 0,2 a $2,6: 1$.

Nas características morfológicas estudadas e discutidas neste trabalho não houve efeito das doses de nitrogênio aplicadas, indicando que este fator não influenciou no comportamento do sistema radical. Hill et al. (2006) não observaram alterações nas características morfológicas de raízes em gramíneas temperadas perenes com relação a aplicação de $\mathrm{N}$, atribuindo a este fator pouco 
impacto sobre estas características. Por outro lado, Giacomini et al. (2005) trabalhando com pastagens tropicais do gênero Panicum obtiveram redução do comprimento e da área de raízes quando aplicado doses de nitrogênio superiores a 150 kg.ha-1, mostrando assim possível comportamento distintos entre pastagens temperadas e tropicais, e de ciclos diferentes.

\section{Conclusão}

A presença do pastejo com ajuste de taxa de lotação pouco influenciou no crescimento das raízes da mistura aveia preta e azevém anual. Contudo, favoreceu o comprimento, a área da superfície, o diâmetro médio e o volume de raízes, mas reduziu a massa especifica e a relação parte aérea:raiz.

As doses de nitrogênio utilizadas neste experimento não alterou o crescimento das raízes da mistura aveia preta e azevém anual.

\section{Referências}

ARREDONDO, J. T.; JOHNSON, D. A. Root architecture and biomass allocation of three range grasses in response to non-uniform supply of nutrients and shoot defoliation. New Phytologist, Cambridge, v. 143, n. 2, p. 373-385, 1999.

BALIGAR, V. C.; FAGERIA, N. K.; ELRASHIDI, M. A. Toxitity and nutrient constraints on root growth. Hort Science, Alexandria, v. 33, n. 6, p. 960-965, 1998.

BOHM, W. Methods of studying root systems. Berlin: Springler-Verlag, 1979. $188 \mathrm{p}$.

BOSEMARK, N. O. The influence of nitrogen on root development. Physiologia Plantarum, Sweden, v. 7, n. 3, p. 497-502, 1954.

CALDWELL, M. M. Competition between roots in natural communities. In: GREGORY, P. J.; LAKE, J. V.; ROSE, D. A. (Ed.). Root development and function. New York: Cambridge University Press, 1987. p. 167-185.

CECATO, U.; CANO, C. C. P.; BORTOLO, M.; HERLING, V. R.; CANTO, M. W.; CASTRO, C. R. C. Teores de carboidratos não-estruturais, nitrogênio total e peso de raízes em coastacross-1 (Cynodon dactylon (L.) Pers) pastejado por ovinos. Revista Brasileira de Zootecnia, Viçosa, MG, v. 30, n. 3, p. 644-650, 2001.
COUPLAND, R. T. Conclusions. In.: COUPLAND, R. T. (Ed.). Grassland ecosystems of the world: analysis of grasslands and their uses. London: Cambridge University Press, 1979. p. 335-355.

DA CUNHA, F. F.; RAMOS, M. M.; ALENCAR, C. A. B.; MARTINS, C. E.; CÓSER, A. C.; OLIVEIRA, R. A. Sistema radicular de seis gramíneas irrigadas em diferentes adubações nitrogenadas e manejos. Acta Scientiarum. Agronomy, Maringá, v. 32, n. 2, p. 351-357, 2010.

DONAGHY, D. J.; FULKERSON, W. J. The impact of defoliation frequency and nitrogen fertilizer application in spring on summer survival of perennial ryegrass under grazing in subtropical Australia. Grass and Forage Science, Oxford, v. 57, n. 4, p. 351-359, 2002.

EISSENSTAT, D. M.; WELLS, C. E.; YANAI, R. D.; WHITBECK, J. L. Building roots in a changing environment: implications for root longevity. New Phytologist, Cambridge, v. 147, n. 1, p. 33-42, 2000.

EISSENSTAT, D. M.; YANAI, R. D. The ecology of root lifespan. Advances in Ecological Research, v. 27, n. 1, p. 2-60, 1997.

EMPRESA BRASILEIRA DE PESQUISA AGROPECUÁRIA - EMBRAPA. Centro Nacional de Pesquisa de Solos. Sistema brasileiro de classificação de solos. Brasília: Embrapa Produção de Informação; Rio de Janeiro: Embrapa Solos, 2006. 312 p.

FLOSS, E. L. Fisiologia das plantas cultivadas. 5. ed. Passo Fundo: UPF, 2011. 733 p.

FRANK, D. A. Drought effects on aboveground and belowground production in a temperate grazed grassland ecosystem. Oecologia, Berlim, v. 152, n. 1, p. 131-139, 2007.

GIACOMINI, A. A.; MATTOS, W. T.; MATTOS, H. B.; WERNER, J. C.; CUNHA, E. A.; CARVALHO, D. D. Crescimento de raízes dos capins Aruana e Tanzânia submetidos a duas doses de nitrogênio. Revista Brasileira de Zootecnia, Viçosa, MG, v. 34, n. 4, p. 1109-1120, 2005.

GILL, R. A.; JACKSON, R. B. Global patterns of root turnover for terrestrial ecosystems. New Phytologist, Cambridge, v. 147, n. 1, p. 13-31, 2000.

GREENWOOD, K. L.; McKENZIE, B. M. Grazing effects on soil physical properties and the consequences for pastures: a review. Australian Journal of Experimental Agriculture, Collingwood, v. 41, n. 8, p. 1231-1250, 2001.

HAVEN, P. G.; EVERT, R. F.; EICHHORN, S. E. Biologia vegetal. 5. ed. Rio de Janeiro: Guanabara Koogan, 1996. 728 p. 
HILL, J. O.; SIMPSON, R. J.; MOORE, A. D.; CHAPMAN, D. F. Morphology and response of roots of pasture species to phosphorus and nitrogen nutrition. Plant and Soil, The Hague, v. 286, n. 1, p. 7-19, 2006.

HUNT, H. W.; MORGAN, J. A.; READ, J. J. Simulating growth and root-shoot partitioning in prairie grasses under elevated atmospheric $\mathrm{CO}_{2}$ and water stress. Annals of Botany, London, v. 81, n. 4, p. 489-501, 1998.

IDO, O. T. Desenvolvimento radicial e caulinar, de três variedades de cana-de-açúcar, em rizotron, em dois substratos. 2003. Tese (Doutorado em Ciências) - Curso de Pós-Graduação em Agronomia, Produção Vegetal, Universidade Federal do Paraná, Curitiba.

INSTITUTO NACIONAL DE METEOROLOGIA INMET. Banco de dados históricos-BDMEP. 2013. Disponível em: <http://www.inmet.gov.br/portal/>. Acesso em: 04 jan. 2013.

JOHANSSON, G. Carbon distribuition in grass (Festuca arundinacea) during regrowth after cutting - Utilization of stored and newly assimilated carbon. Plant and Soil, The Hague, v. 151, n. 1, p. 11-20, 1993.

LAWLOR, D. W. Carbon and nitrogen assimilation in relation to yield: mechanisms are the key understanding production systems. Journal of Experimental Botany, Oxford, v. 53, n. 370, p. 773-787, 2002.

LEMAIRE, G. The physiology of grass growth under grazing: tissue turn-over. In: SIMPÓSIO INTERNACIONAL SOBRE PRODUÇÃO ANIMAL EM PASTEJO, 1997, Viçosa, MG. Anais... Viçosa, MG: Universidade Federal de Viçosa, 1997. p. 117-144.

LEMAIRE, G.; AGNUSDEI, M. Leaf tissue turn-over and efficiency of herbage utilization. In: LEMAIRE, G.; HODGSON, J.; MORAES, A.; CARVALHO, P. C. F.; NABINGER, C. (Ed.). Grassland ecophysiology and grazing ecology. Nova York: CAB International, 2000. p. $265-288$.

MACKIE-DAWSON, L. A. Nitrogen uptake and root morphological responses of defoliated Lolium perenne (L.) to a heterogeneous nitrogen supply. Plant Soil, The Hague, v. 209, n. 1, p. 111-118, 1999.

MORVAN-BERTRAND, A.; PAVIS, N.; BOUCAUD, J.; PRUD'HOMME, M. P. Partitioning of reserve and newly assimilated carbon in roots and leaf tissues of Lolium perenne during regrowth after defoliation: Assessment by $13 \mathrm{C}$ steady-state labeling and carbohydrate analysis. Plant Cell \& Environment, Oxford, v. 22, n. 9, p. 10971108, 1999.

MOTT, G. O.; LUCAS, H. L. The design, conduct and interpretation of grazing trials on cultivated and improved pastures. In: INTERNATIONAL GRASSLAND CONGREES, 6., 1952, State College. Proceedings... State College: Pennsylvania State College Press, 1952. p. 1380-1385.

PELLEGRINI, L. G.; MONTEIRO, A. L. G.; NEUMANN, M.; MORAES, A.; BONA FILHO, A.; MOLENTO, M. B. PELLEGRINI, A. C. R. S. Produção de cordeiros em pastejo contínuo de azevém anual submetido à adubação nitrogenada. Ciência Rural, Santa Maria, v. 40, n. 6, p. 1399-1404, 2010.

RÉGENT INSTRUMENTS. Win/MacRHIZO V4.1c: Introduction manual. Québec: Régent Instruments Inc., 1999a. 36 p.

Win/MacRHIZO V4.1c: reference. Québec: Régent Instruments Inc., 1999b. 36 p.

RYLE, G. J. A. Distribution pattern of assimilated 14C in vegetative and reproductive shoots of Lolium perenne and L. temulentum. Annals of Applied Biology, London, v. 66, n. 97 , p. $155-167,1970$.

RYSER, P. The importance of tissue density for growth and life-span of leaves and roots: comparison of five ecologically contrasting grasses. Functional Ecology, Londres, v. 10, n. 6, p. 717-723, 1996.

SARMENTO, P.; RODRIGUES, L. R. A.; LUGÃO, S. M. B.; CRUZ, M. C. P.; CAMPOS, F. P de; FERREIRA, M. E.; OLIVEIRA, R. F. Sistema radicular do Panicum maximum Jacq. cv. IPR-86 milênio adubado com nitrogênio e submetido à lotação rotacionada. Revista Brasileira de Zootecnia, Viçosa, MG, v. 37, n. 1, p. $27-$ 34, 2008.

SNAYDON, R. W. The productivity of C3 and C4 plants: a reassessment. Functional Ecology, Londres, v. 5, n. 3, p. 321-333, 1991.

THORNTHWAITE, C. W.; MATHER, J. R. The water balance. Centerton, NJ: Drexel Institute of Technology Laboratory of Climatology, 1955. 104 p. (Publications in Climatology, v. 8, n. 1).

THORNTON, B.; MILLARD, P. Effects of severity of defoliation on root functioning in grasses. Journal of Range Management, Tucson, v. 49, n. 5, p. 443-447, 1996.

TRACY, B. F.; ZHANG, Y. Soil compactation, corn yield response, and soil nutriente pool dynamics within na integrated croplivestock system in Ilinois. Crop Science, Madison, v. 48, n. 3, p. 1211-1218, 2008.

VAN SOEST, P. J. Nutritional ecology of the ruminant. 2. ed. Ithaca: Cornell University Press, 1994. 476 p. 
